\title{
Clinical and epidemiological profiles including meteorological factors of low respiratory tract infection due to human rhinovirus in hospitalized children
}

\author{
Yongdong Yan ${ }^{\dagger}$, Li Huang ${ }^{\dagger}$, Meijuan Wang, Yuqing Wang, Wei Ji, Canhong Zhu* and Zhengrong Chen ${ }^{*}$
}

\begin{abstract}
Background: Lower respiratory tract infection (LRTI) is a major cause of morbidity and mortality in children. Human rhinovirus (HRV) is confirmed to be associated with pediatric lower respiratory tract infection. Seasonal and meteorological factors may play a key role in the epidemiology of HRV. The purposes of this study were to investigate the frequency, seasonal distribution, and clinical characteristics of hospitalized children with LRTI caused by HRVs. In addition, associations between incidence of HRVs and meteorological factors in a subtropical region of China were discussed.

Methods: Hospitalized children $<14$ years old admitted to the Respiratory Department of the Children's Hospital, which is affiliated to Soochow University, between January 1, 2013 and December 31, 2015, were enrolled in this study. Multipathogens were detected in nasopharyngeal aspirate samples. Meanwhile, meteorological factors were recorded.

Results: The average incidence of HRVs infection was 11.4\% (707/6194) and 240 cases of which were co-infection cases with other pathogens. Children with co-infection presented more frequent fever and tachypnea compared to children infected with HRVs only (both $P<0.05$ ). Among 707 HRV positive children, the mean age was 23.2 months (range 1 to 140 months). Among all respiratory infections, the highest incidence of HRVs cases occurred in children age 13-36 months old $(15.1 \%, 203 / 1341)$. Of all 228 HRV cases in 2014, 85 cases (37.3\%) were HRV-C positive. HRVs and HRV-C infection occurred throughout the year during the study period, although a higher incidence was observed in summer and autumn seasons. HRVs or HRV-C incidence in hospitalized children with LRTI was associated with the monthly mean temperature (both $P<0.05$ ).

Conclusion: HRV was one of the most common viral pathogen detected in hospitalized children with LRTI at the Children's Hospital of Suzhou, China, and had its own seasonal distribution including HRV-C, which was partly caused by temperature.
\end{abstract}

Keywords: Human Rhinovirus, Meteorological factors, Lower respiratory tract infection, Children, Epidemiology

\section{Background}

Viruses are the most frequent cause of acute respiratory infections and are a leading cause of childhood mortality [1]. However, the etiological agents remain unknown in a significant proportion of cases. Human rhinovirus (HRV), first discovered in the 1950's, is a member of the

\footnotetext{
* Correspondence: Canhong_Zhu@gmail.com; chen_zheng_rong@163.com ${ }^{\dagger}$ Equal contributors

Department of Respiratory Disease, Children's Hospital of Soochow University, NO.303, Jingde Road, Suzhou, Jiangsu Province 215003, People's Republic of China
}

family Picornaviridae, genus Enterovirus, and is one of the most frequent cause of acute respiratory infections. Recent studies showed that HRV not only causes mild upper respiratory tract infections but also associated with lower respiratory tract infections (LRTIs) [2], acute asthma exacerbations [3], recurring wheeze [4] and severe cases with bronchiolitis [5] particularly in infants and early childhood [6].

Global HRVs activity varies substantially from year to year among different populations and regions and recent epidemiological data show that HRVs are present all year 
round with different incidence rates from $16-68.5 \%$ in children with LRTI $[2,7-9]$. HRVs are the most common cause of respiratory viral illness during the spring, summer, and fall seasons, while respiratory syncytial virus (RSV) and influenza virus (IV) predominate in the winter $[10,11]$. However, no seasonal pattern of HRVs was found in Istanbul, Turkey [12]. In general, seasonal distribution of HRVs varies in different regions and is still poorly understood. Recent studies show that meteorological factors have the greatest potential to play key roles in epidemics and seasonality of respiratory virus infection [13-15]. Among these meteorological factors, temperature and humidity are frequently associated with respiratory virus infection. However, few studies investigated the association between HRVs activity and meteorological factors in subtropical area of China.

The objective of this study was to ascertain the frequency, seasonal and clinical characteristics of HRVs in hospitalized children with LRTI and evaluate the effects of meteorological factors on the incidence of HRV in a subtropical area in China.

\section{Methods}

\section{Study design}

From January 2013 to December 2015, children < 14 years old with LRTIs admitted to Department of Respiratory Disease in Children's Hospital of Soochow University were prospectively enrolled in this study. After completing a full clinical record, nasopharyngeal aspirate (NPA) was performed on each child enrolled as described previously [16] and stored at $4{ }^{\circ} \mathrm{C}$ until sent to the clinical laboratory for further direct immunofluorescence assay and polymerase chain reactions (PCR) analysis. Pending the molecular diagnostic, all samples were stored at $-80{ }^{\circ} \mathrm{C}$ after DNA or RNA extraction. LRTI (bronchiolitis, bronchitis, pneumonia and asthma exacerbation) was defined by the presence of signs and symptoms of an acute respiratory infection (cough, nasal discharge, with or without fever), lower respiratory signs (tachypnea, retractions, prolonged expiratory time, or crackles/wheezing on auscultation) and radiologic evidence of LRTI. Chest radiography was performed using standard equipment and radiographic techniques, and reviewed by the radiologists in digital format. Generally speaking, bronchiolitis presents bilateral hyperinflation with variable, patchy areas of atelectasis. Pneumonia presents increased shadowing or consolidation while increased lung markings shows in bronchitis or asthma exacerbation. Children with a history of chronic lung disease, underlying immunodeficiency states, or preexisting cardiac, renal, neurologic, or hepatic dysfunction, or bronchopulmonary malformation were excluded from the study. This study was conducted with the approval of the Institutional Human Ethical Committee of Children's Hospital of Soochow University. An informed consent was obtained from all the subjects or guardians who participated in this study.

\section{Detection of HRVs and HRV-C using real time PCRs}

In present study, a sensitive quantitative PCR method targeted a 210-bp region from the conserved 5' untranslated region (5' UTR) was used to screen for HRV modified from a previous study [17]. The primers and probe sequences were HRV-F: 5'-TGGACAGGGTGTGAAGA GC -3';HRV-R:5'-CAAAGTAGTCGGTCCCATCC-3' ; HRV-probe: FAM-TCCTCCGGCCCCTGA ATG-TAMRA . Nucleic acids were extracted from NPA samples with TRIzol reagent (Life Technologies, Carlsbad, USA) following the protocol provided by the manufacturer. A final $200 \mu \mathrm{l}$ of RNA was eluted and reverse transcription reactions were performed with M-MLV reverse transcriptase (Promega, Madison, USA) and random hexamers (Sangon Biotech, Shanghai, China) for cDNA synthesized at $37^{\circ} \mathrm{C}$ for $60 \mathrm{~min}$ according to the manufacturer's specifications. PCRs were performed in a volume of $25 \mu \mathrm{l}$ containing $3 \mu \mathrm{l}$ of sample DNA, $0.25 \mu \mathrm{l}$ of $5 \mathrm{U} / \mu \mathrm{l}$ TaqMan (Promega, Madison, USA), $75 \%$ DEPC treated water $14.75 \mu \mathrm{l}$, buffer solution $2.5 \mu \mathrm{l}$, $25 \mathrm{mM} \mathrm{MgSO}_{4} 2 \mu \mathrm{l}, 10 \mathrm{mM}$ dNTP $1 \mu \mathrm{l}$, forward, reverse primers $(1.5 \mu \mathrm{mol} / \mathrm{L})$ and probe $(0.2 \mu \mathrm{mol} / \mathrm{L})$ each $0.5 \mu \mathrm{l}$. The PCR conditions were as follows: reverse transcription, $30 \mathrm{~min}$ at $50{ }^{\circ} \mathrm{C}$; polymerase activation, $15 \mathrm{~min}$ at $95^{\circ} \mathrm{C}$; and 45 cycles of $30 \mathrm{~s}$ at $95{ }^{\circ} \mathrm{C}$ and $60 \mathrm{~s}$ at $60^{\circ} \mathrm{C}$. The concentration of each detected sample was then calculated automatically according to standard curve.

From January 2014 to December 2014, positive HRV samples were used to determine HRV-C strain. According to analysis of HRV VP4/VP2 coding region sequences from GenBank, the conserved sequence (8-37 amino acid) from VP2 was confirmed to differentiate HRV-C from HRV-A and -B after comparison of 52 newly identified HRV-C subtypes using a phylogenetic tree. The degenerate primers were designed according to the conserved sequence. The degenerate primers sequences were HRV-F: 5'-GGNWWBTCYGATAGGCTHAA-3'; HRV-R:5'-TANBBDGGCCAYTCHCCRTANGC-3' $(\mathrm{N}=\mathrm{A}, \mathrm{T}$, $\mathrm{C}$ or $\mathrm{G}, \mathrm{W}=\mathrm{A}$ or $\mathrm{T}, \mathrm{B}=\mathrm{G}, \mathrm{T}$ or $\mathrm{C}, \mathrm{Y}=\mathrm{C}$ or $\mathrm{T}, \mathrm{H}=\mathrm{A}, \mathrm{T}$ or $\mathrm{C}, \mathrm{D}=\mathrm{G}, \mathrm{A}$ or $\mathrm{T}, \mathrm{R}=\mathrm{A}$ or $\mathrm{G}, \mathrm{V}=\mathrm{G}, \mathrm{A}$ or $\mathrm{C}$ ). Compared to positive control sample of HRV-51 strain, the optimal concentration of primers and melting temperature were obtained. Then all the screened HRV positive samples were amplified by real time PCR and HRV-C subtypes could be confirmed by comparing to high-resolution melting curve of HRV-C51.

\section{Detection of other common viruses and Mycoplasma pneumoniae (MP)}

Samples were equally analyzed for seven common viruses, including RSV, IV-A and IV-B, parainfluenza 
viruses 1, 2, 3 (PIV-1, 2, 3), and adenovirus (ADV) using direct immunofluorescence (DFA) with virus-specific fluorescence-labeled monoclonal antibodies (Diagnostic Hybrids, Athens, USA) and ultraviolet light microscopy. Human metapneumovirus (hMPV) were detected by reverse transcription PCR whereas human bocavirus (HBoV) and Mycoplasma pneumonia (MP) were detected by real time PCR respectively as previously described [14]. Briefly, for hMPV detection, primers were designed to specifically amplify the $\mathrm{N}$ gene (213 bps). The forward and reverse primers were hMPV-F: 5'AACCGTGTACTAAGTGATGCACTC-3' and hMPV-R: 5'CATTGTTTGACCGGCCCCATAA-3', respectively. For HBoV VP1 gene detection, the primers and probe sequences were HBoV-F: 5'-TGACATTCAACTACCAACA ACCTG-3';HBoV-R:5'-CAGATCCTTTTCCTCCTCCAAT AC-3' ;HBoV-probe: FAM-AGCACCACAAAACACCTCA GGGG-TAMRA. As for MP detection, another fluorescent real-time PCR was performed to identify the $16 \mathrm{~S}$ rRNA gene of MP. The primers and probe sequences were MP-F: 5'-GCAAGGGTTCGTTATTTG-3' and MP-R: 5'-CGCC TGCGCTTGCTTTAC-3, and MP-probe: FAM-AGGTA ATGGCTAGAGTTTGACTG-TAMRA. MP and HBoV positive samples were defined with a concentration of DNA $>2.5 \times 10^{3}$ copies $/ \mathrm{ml}$ to exclude the $\mathrm{MP}$ or $\mathrm{HBoV}$ colonization.

\section{Meteorological data collection}

Meteorological data for Suzhou, including daily mean temperature $\left({ }^{\circ} \mathrm{C}\right)$, mean relative humidity (\%), total month rainfall $(\mathrm{mm})$, sum of sunshine (h), and mean wind velocity $(\mathrm{m} / \mathrm{s})$, were obtained from Suzhou Weather Bureau at longitude $120^{\circ} 6^{\prime}$ east and latitude $31^{\circ} 3^{\prime}$ north, which is located $8 \mathrm{~km}$ away from the hospital. Meteorological data were obtained hourly, and average daily values were calculated. Monthly means were calculated using the daily means for temperature, relative humidity, and wind velocity. Total rainfall and hours of sunshine were calculated as a total measurement for the month.

\section{Statistical analysis}

The continuous variables were compared using the Student $\mathrm{t}$ test or Mann-Whitney $U$ test if the data were abnormal in distribution. Categorical data were analyzed using the Mentel-Haenszel or chi-squared $(x 2)$. Correlations of incidence of HRV with meteorological factors were evaluated using Pearson's or Spearman rank correlation. Because of colinearity between meteorological factors, associations between meteorological factors and HRV incidence were also analyzed using Linear Regression. $P<0.05$ was considered to be statistically significant.

\section{Results}

\section{Viral and atypical bacterial etiology of LRTIs}

A total of 6196 NPA samples were available and 276 children were not enrolled because of a refusal to participate from their parent or presenting underlying disease. Of 6196 NPA samples, 3882 (62.7\%) were positive for at least one pathogen and the most commonly identified pathogen was Mycoplasma pneumonia (MP) (22.1\%, 1369/6196), followed by RSV (12.0\%, 744/6196), HRV (11.4\%, 707/6196), human bocavirus (HBoV) (5.7\%, 354/6196), PIV-3 (5.1\%, 315/6196), human metapneumovirus (hMPV) $(3.7 \%, 230 / 6196)$, adenovirus (ADV) $(1.1 \%, 69 / 6196)$, parainfluenza virus 1 (PIV-1) $(0.9 \%, 55 /$ 6196), IV-A $(0.5 \%, 32 / 6196)$, and parainfluenza virus 2 (PIV-2) $(0.1 \%, 7 / 6196)$. Among 707 HRV-positive cases, $467(66.1 \%)$ were infected only with HRV and 240 (33.9\%) were co-infected with other pathogens. The most commonly co-detected pathogen with HRV was Mycoplasma pneumoniae, followed by $\mathrm{HBoV}$ and RSV (Table 1). Of all the 228 HRVs cases in 2014, HRV-C was detected in 85 cases and accounting for $37.3 \%$.

\section{Demographic and clinical characteristics of children infected by HRV with or without co-infection}

Of the $707 \mathrm{HRV}$ positive cases, the mean age was 23.2 months (range 1 to 140 months) and the ratio of male to female was $2.3: 1$ and slightly higher than 1.7:1 of non-HRV infected cases $(P=0.052)$. HRV affected mostly children aged 13-36 months with an incidence of $15.1 \%(203 / 1341)$. The HRV incidence in different age groups was as follows: $1-6$ months $(9.3 \%, 192 / 2065)$, 7-12 months $(13.3 \%, 181 / 1357,13-36$ months (15.1\%, 203/1341), 37-60 months $(9.8 \%, 67 / 682)$, and $>$ 60 months $(8.5 \%, 64 / 749)$ and HRV incidence was significantly different between groups $(\chi 2=40.31, P<$ $0.0001)$ as shown in Fig. 1. The demographic and clinical characteristics of cases with single HRV infection and co-infection are summarized and compared in Table 2.

Table 1 Frequency of HRV infection with other respiratory pathogens in children with LRTIs

\begin{tabular}{lll}
\hline Pathogen distribution of co-infections with HRV & Cases & $\%$ \\
\hline Mycoplasma pneumoniae & 121 & 50.4 \\
HBoV & 47 & 19.6 \\
RSV & 27 & 11.3 \\
PIV-3 & 17 & 7.1 \\
ADV & 7 & 2.9 \\
hMPV & 7 & 2.9 \\
More than two pathogens & 14 & 5.8 \\
Total co-infections & 240 & 100 \\
\hline
\end{tabular}

$L R T I$ lower respiratory tract infection, $H R V$ human rhinovirus, $H B O V$ human bocavirus, $R S V$ respiratory syncytial virus, $h M P V$ human metapneumovirus, $P I V$ parainfluenza virus, $A D V$ adenovirus 


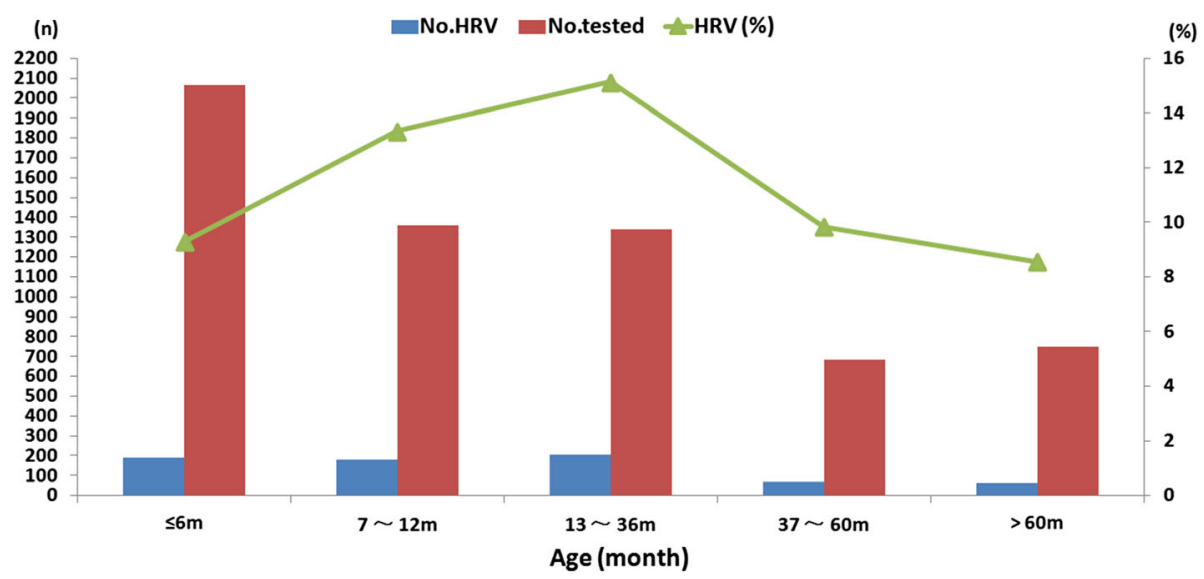

Fig. 1 Age distribution in hospitalized children with lower respiratory tract infection due to human rhinovirus (HRVs) infection

Children with co-infection presented more frequent fever, tachypnea and longer hospital stay compared to children infected with HRVs only (all $P<0.05$ ). However, there was no difference of clinical characteristics between HRV-C infection and HRV-A/B infection (data not shown).

\section{Seasonal distribution of HRV infection and association with meteorological factors}

As shown in Fig. 2, HRVs infection occurred throughout the year during the study period, although a higher

Table 2 Demographic and clinical characteristics of children infected by HRVs with or without co-infection

\begin{tabular}{|c|c|c|c|}
\hline Parameters & Single infection & Co-infections & $P$ Value \\
\hline \multicolumn{4}{|l|}{ Demographic characteristics } \\
\hline Age, mean (25-75\%) & $23.9(5.8-29)$ & $22.0(5.9-31)$ & 0.988 \\
\hline Sex, male (\%) & $310(66.4)$ & $162(67.5)$ & 0.765 \\
\hline $\begin{array}{l}\text { Median duration of stay in } \\
\text { hospital, days }\end{array}$ & $7.6 \pm 2.7$ & $8.4 \pm 2.7$ & 0.017 \\
\hline \multicolumn{4}{|l|}{ Clinical manifestation } \\
\hline Cough, n (\%) & $452(96.8)$ & $232(96.7)$ & 0.931 \\
\hline Wheezing, n (\%) & $225(48.2)$ & $118(49.2)$ & 0.804 \\
\hline Rhinorrhea, n (\%) & $206(44.1)$ & $91(37.9)$ & 0.114 \\
\hline Fever, n (\%) & $186(39.8)$ & $125(52.1)$ & 0.002 \\
\hline Tachypnea, n (\%) & $105(22.5)$ & $74(30.8)$ & 0.016 \\
\hline Dyspnea, n (\%) & $52(11.1)$ & $27(11.3)$ & 0.963 \\
\hline Cyanosis, n (\%) & $10(2.1)$ & $5(2.1)$ & 0.960 \\
\hline \multicolumn{4}{|l|}{ Laboratory examination } \\
\hline White blood cells, $\left(\times 10^{9} / \mathrm{ml}\right)$ & $11.7 \pm 5.0$ & $11.1 \pm 4.3$ & 0.380 \\
\hline Neutrophils, (\%) & $43.7 \pm 21.5$ & $47.9 \pm 20.4$ & 0.173 \\
\hline Platelets, $\left(\times 10^{9} / \mathrm{ml}\right)$ & $380 \pm 121$ & $382 \pm 115$ & 0.920 \\
\hline $\begin{array}{l}\text { C-reaction protein, } \mathrm{mg} / \mathrm{L}, \\
\text { mean }(25 \%-75 \%)\end{array}$ & $5.4(0.1-8.4)$ & $6.3(0.1-11.8)$ & 0.380 \\
\hline
\end{tabular}

incidence was observed in summer and autumn seasons, especially in June 2015 (20.7\%, 28/135). The HRV incidence was $14.7 \%(206 / 1400)$ in autumn, followed by $13.3 \%(203 / 1532)$ in summer, $11.8 \%(190 / 1612)$ in spring, and 6.5\% (108/1652) in winter. The similar seasonality of HRV-C was shown in Fig. 3. The Suzhou area has a subtropical climate. The monthly mean temperature was $18.2 \pm 9.2$ (mean \pm standard deviation) ${ }^{\circ} \mathrm{C}$, relative humidity was $69.7 \pm 7.4 \%$, total rainfall was $100.5 \pm 73.9 \mathrm{~mm}$, sum of sunshine was $181.1 \pm 65.8 \mathrm{~h}$, and wind velocity was $1.8 \pm 0.5 \mathrm{~m} / \mathrm{s}$. The monthly mean data for these meteorological variables over the course of this study are shown in Fig. 2. The associations of total HRVs, HRVs with or without coinfection or HRV-C activity with meteorological factors were performed using Spearman correlations and multivariate regression analysis. Total HRVs, HRVs without coinfection and HRV-C incidence was associated with mean temperature (all $P<0.05$ ). No correlation was found between total HRVs, HRVs without coinfection, HRV-C incidence and other meteorological factors by multivariate regression analysis (Table 3). The incidence of HRVs with coinfection was not associated with all meteorological factors (all $P>0.05)$.

\section{Discussion}

The findings in this study confirmed the hypothesis that HRVs are common pathogen in hospitalized children with lower respiratory tract infection. To our knowledge, this is the first time to explore the associations between HRVs incidence and meteorological factors in a subtropical region of China. In the present study, HRVs was detected in $11.4 \%$ NAP samples collected from January 2013 to December 2015 and this rate is similar to previous report in Lanzhou, China $(13.1 \%, 53 / 406)$ [18]. However, the incidence of this study is lower than previous studies in Turkey (18.4\%), Vietnam (24.2\%) and Thailand 


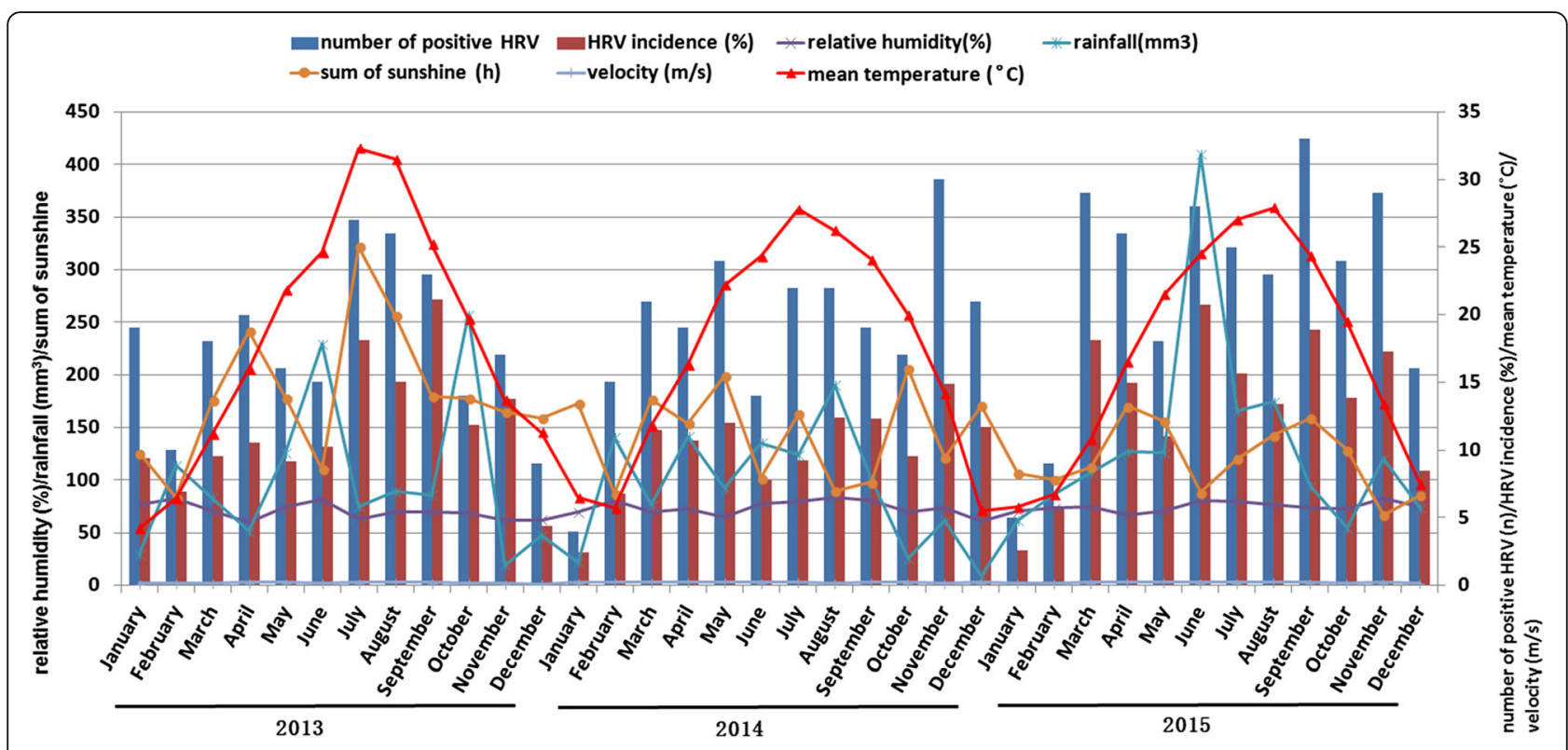

Fig. 2 Seasonal and monthly distribution of human rhinovirus (HRVs) infection and meteorological factors from January 2013 to December 2015

(30\%) $[12,19,20]$. All the studies above show that HRV plays an important role in respiratory tract infections worldwide.

In the present study, $81.3 \%(575 / 707)$ of total HRVs occured in children younger than 36 months, especially in children 13 to 36 months old which is consistent with recent report in Changsha, China [21]. Meanwhile, Linder et al. [22] reported that HRVs is more frequently detected in younger children and infants than in older children. The possible reason is that younger children are more prone to be sick than older children due to their developing immune system and that parents are more likely to take their younger children to the doctor if they are sick. Moreover, only children hospitalized with LRTIs were included in the study. HRV has been considered to be a benign virus causing mild upper respiratory tract infections, but there is evidence that HRV is also involved in LRTIs, more specifically in bronchiolitis [23] and pneumonia [24], which is similar to our study. In addition, infants hospitalized with HRV bronchiolitis have a great risk of asthma later in childhood [25] and HRV infection is associated with exacerbations of asthma [26]. A recent study presumed that HRV-stimulated peripheral blood mononuclear cells increased the gene expression of

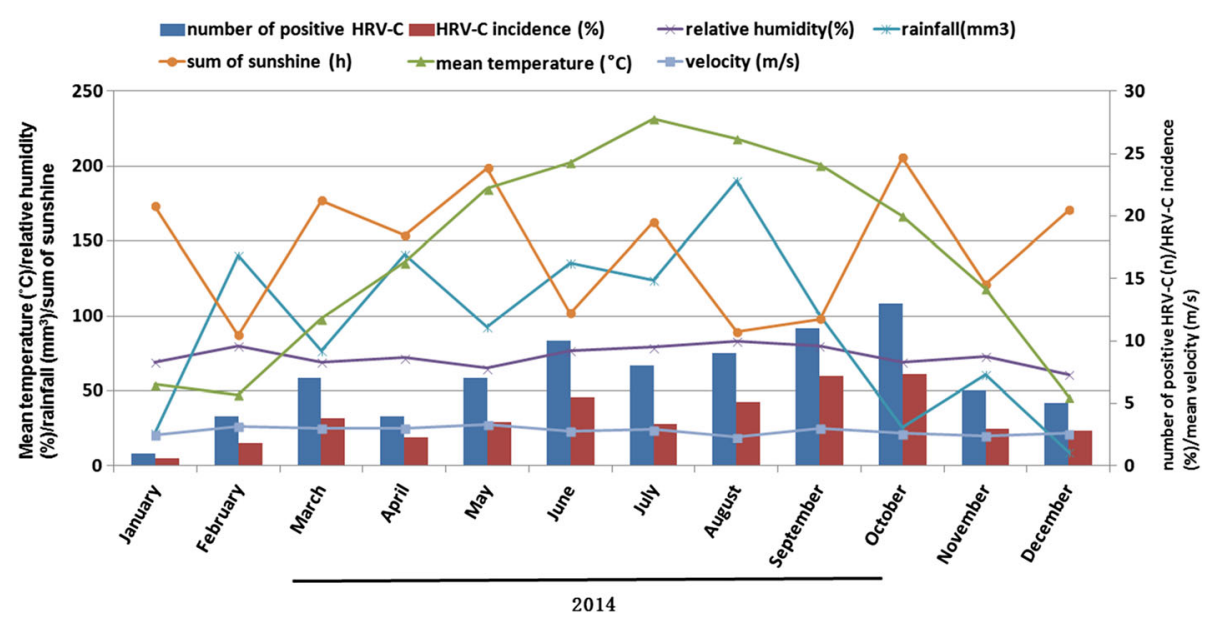

Fig. 3 Seasonal and monthly distribution of HRV-C infection and meteorological factors from January 2014 to December 2014 
Table 3 Associations of HRVs incidence and meteorological factors

\begin{tabular}{|c|c|c|c|c|c|c|c|c|c|c|c|c|}
\hline \multirow{3}{*}{ Climate factors } & \multicolumn{4}{|c|}{ total HRVs } & \multicolumn{4}{|c|}{ HRVs without coinfection } & \multicolumn{4}{|l|}{ HRV-C } \\
\hline & \multicolumn{2}{|c|}{ correlation } & \multicolumn{2}{|c|}{ Multivariate regression } & \multicolumn{2}{|c|}{ correlation } & \multicolumn{2}{|c|}{ Multivariate regression } & \multicolumn{2}{|c|}{ correlation } & \multicolumn{2}{|c|}{ Multivariate regression } \\
\hline & $r_{s}$ & $P$ value & $\beta$ & $P$ value & $\mathrm{r}_{\mathrm{s}}$ & $P$ value & $\beta$ & $P$ value & $r_{s}$ & $P$ value & $\bar{\beta}$ & $P$ value \\
\hline Temperature $\left({ }^{\circ} \mathrm{C}\right)$ & 0.545 & 0.001 & 0.304 & 0.001 & 0.648 & $<0.001$ & 0.709 & 0.002 & 0.660 & 0.019 & 1.002 & 0.032 \\
\hline Relative humidity (\%) & 0.041 & 0.811 & -0.028 & 0.850 & 0.030 & 0.860 & -0.262 & 0.326 & 0.268 & 0.399 & -0.041 & 0.946 \\
\hline Total rainfall (mm) & 0.322 & 0.056 & 0.113 & 0.482 & 0.360 & 0.031 & 0.173 & 0.345 & 0.109 & 0.736 & -0.747 & 0.176 \\
\hline Sum of sunshine (h) & 0.166 & 0.332 & -0.039 & 0.804 & 0.212 & 0.215 & -0.174 & 0.549 & -0.111 & 0.731 & -0.503 & 0.368 \\
\hline Wind velocity (m/s) & 0.168 & 0.328 & -0.012 & 0.940 & 0.106 & 0.537 & -0.111 & 0.454 & -0.067 & 0.837 & 0.130 & 0.667 \\
\hline
\end{tabular}

$P<0.05$ indicates significant difference

HRV human rhinovirus

ORMDL3 and of GSDMB which was associated with 17q21 variants and correlated with development of asthma [27]. Furthermore, a previous study reported that HRV-C causes more severe respiratory illness in children than HRV-A or $-B[28,29]$. In present study, no significant difference of clinical characteristics was found between HRV-C and HRV A/B infection. However, we found that children with co-infection were more severe compared to children infected with HRV only.

Consistent with our study, HRV is the most common cause of respiratory viral illness during the spring, summer, and fall seasons, while RSV predominates in the winter [30]. Factors such as meteorological factors may have an impact in survival and contribute to the seasonal outbreaks of respiratory viruses [13]. Therefore, the recent discussions over the impacts of global warming on the terrestrial environment have awoken the interest of the association between meteorological factors and respiratory tract infections. In previous studies, high relative humidity had been proved to be associated with increasing survival of rhinovirus [13, 31] and it was associated with greater amounts of sick leave in workspaces using humidifiers [32]. However, mean temperature other than relative humidity was positively associated with HRVs or HRV-C incidence in present study. Further studies are necessary to determine why various meteorological factors are associated with HRVs infections in different geographic locations.

Our study has several limitations. First of all, 3-year period of this present study was shorter than other long-term investigations which could cause bias of the HRVs prevalence. Secondly, the data analysis alone may not serve as a conclusive interpretation, since any of associations with meteorological factors may be an indication of other social or environmental factors that also vary with the seasons. In addition, the present study was based on a single center. Taken together, these limitations might have potential biases on the research results.

\section{Conclusions}

HRV was one of the most common pathogen found in hospitalized children aged less than 3 years old with LRTI at the Children's Hospital of Soochow University, located in a subtropical region of China. The mean temperature of the month was shown to be associated with the seasonal distribution of HRV infection in these cases.

\section{Abbreviations}

ADV: Adenovirus; DFA: Direct immunofluorescence; HBoV: Human bocavirus; hMPV: Human metapneumovirus; HRV: Human rhinovirus; IV: Influenza virus; LRTI: Lower respiratory tract infection; MP: Mycoplasma pneumonia; NAP: Nasopharyngeal aspirate; PCR: Polymerase chain reactions; PIV: Parainfluenza virus; RSV: Respiratory syncytial virus

\section{Acknowledgements}

We thank the members of the research team, laboratory staff and all cooperating institutes for their dedication to the project. Most of all, we are indebted to all participating children and their families.

\section{Funding}

This work was supported by National Natural Science Foundation of China [Zhengrong Chen, grant number 81401296; Wei Ji, grant number 81570016], Suzhou Science and Technology Projects [Zhengrong Chen, grant number SYS201350; Yongdong Yan, grant number SYS201435], Science and Technology Projects of Jiangsu Provincial Commission of Health and Family Planning [Zhengrong Chen, Q201403], Science and Technology Projects of Chinese Traditional Medicine Bureau of Jiangsu Province [Zhengrong Chen, grant number YB2015176], and Science and Technology Projects of Suzhou sanitary bureau [Yongdong Yan, grant number LCZX201409], Social Development Projects of Suzhou [Yongdong Yan, grant number, SS201537], Projects of National Provincial Commission of Health and Family Planning [Chuanhe Liu, grant number 201502025], Jiangsu Province's Social Development Project [Chuangli Hao, BE2016676].

Availability of data and materials

All data is available.

\section{Authors' contributions}

YY, LH and ZC have made substantial contributions for the concept and design of the main manuscript text; YW, CZ and WJ collected clinical and laboratory data; MW analyzed and interpreted the data. All authors read and approved the final manuscript.

\section{Competing interests}

The authors declare that they have no competing interests.

\section{Consent for publication}

All authors have read and approved the content, and they agree to submit it for consideration for publication in the journal. 


\section{Ethics approval and consent to participate}

This study was conducted with the approval of the Institutional Human Ethical Committee of Children's Hospital of Soochow University (reference number 2013018).

\section{Received: 3 August 2016 Accepted: 28 February 2017}

Published online: 07 March 2017

\section{References}

1. Williams BG, Gouws E, Boschi-Pinto C, Bryce J, Dye C. Estimates of worldwide distribution of child deaths from acute respiratory infections. Lancet Infect Dis. 2002;2:25-32.

2. O'Callaghan-Gordo C, Bassat Q, Díez-Padrisa N, Morais L, Machevo S, Nhampossa $T$, et al. Lower respiratory tract infections associated with rhinovirus during infancy and increased risk of wheezing during childhood. A cohort study. PLoS One. 2013;8:e69370

3. Soto-Quiros M, Avila L, Platts-Mills TA, Hunt JF, Erdman DD, Carper H, et al High titers of IgE antibody to dust mite allergen and risk for wheezing among asthmatic children infected with rhinovirus. J Allergy Clin Immunol. 2012:129:1499-505.

4. Midulla F, Pierangeli A, Cangiano G, Bonci E, Salvadei S, Scagnolari C, et al. Rhinovirus bronchiolitis and recurrent wheezing: 1-year follow-up. Eur Respir J. 2012;39:396-402.

5. Papadopoulos NG, Moustaki M, Tsolia M, Bossios A, Astra E, Prezerakou A, et al. Association of rhinovirus infection with increased disease severity in acute bronchiolitis. Am J Respir Crit Care Med. 2002;165:1285-89.

6. Kieninger $E$, Fuchs $O$, Latzin P, Frey $U$, Regamey $N$. Rhinovirus infections in infancy and early childhood. Eur Respir J. 2013;41:443-52.

7. Guerrier G, Goyet S, Chheng ET, Rammaert B, Borand L, Te V, et al. Acute viral lower respiratory tract infections in Cambodian children: clinical and epidemiologic characteristics. Pediatr Infect Dis J. 2013;32:e8-13.

8. Cox DW, Bizzintino J, Ferrari G, Khoo SK, Zhang G, Whelan S, et al. Human rhinovirus species $C$ infection in young children with acute wheeze is associated with increased acute respiratory hospital admissions. Am J Respir Crit Care Med. 2013;188:1358-64.

9. Fry AM, Lu X, Olsen SJ, Chittaganpitch M, Sawatwong P, Chantra S, et al. Human rhinovirus infections in rural Thailand: epidemiological evidence for rhinovirus as both pathogen and bystander. PLoS One. 2011;6:e17780.

10. Miller EK, Lu X, Erdman DD, Poehling KA, Zhu Y, Griffin MR, et al. Rhinovirusassociated hospitalizations in young children. J Infect Dis. 2007;195:773-81.

11. Vesa S, Kleemola M, Blomqvist S, Takala A, Kilpi T, Hovi T. Epidemiology of documented viral respiratory infections and acute otitis media in a cohort of children followed from two to twenty-four months of age. Pediatr Infect Dis J. 2001;20:574-81.

12. Bicer $S$, Giray $T$, Çöl D, Erdağ GÇ, Vitrinel A, Gürol Y, et al. Virological and clinical characterizations of respiratory infections in hospitalized children. Ital J Pediatr. 2013;39:22.

13. du Prel JB, Puppe W, Gröndahl B, Knuf M, Weigl JA, Schaaff F, et al. Are meteorological parameters associated with acute respiratory tract infections? Clin Infect Dis. 2009:49:861-68.

14. Chen ZR, Ji W, Wang YQ, Yan YD, Shao XJ, Zhang XL, et al. Etiology of acute bronchiolitis and the relationship with meteorological conditions in hospitalized infants in China. J Formos Med Assoc. 2014;113:463-9.

15. Wang Y, Chen Z, Yan YD, Guo H, Chu C, Liu J, et al. Seasonal distribution and epidemiological characteristics of human metapneumovirus infections in pediatric inpatients in Southeast China. Arch Virol. 2013;158:417-24.

16. Chen Z, Ji W, Wang Y, Yan Y, Zhu H, Shao X, et al. Epidemiology and associations with climatic conditions of mycoplasma pneumoniae and chlamydophila pneumoniae infections among Chinese children hospitalized with acute respiratory infections. Ital J Pediatr. 2013;39:34.

17. Granados A, Luinstra K, Chong S, Goodall E, Banh L, Mubareka S, et al. Use of an improved quantitative polymerase chain reaction assay to determine differences in human rhinovirus viral loads in different populations. Diagn Microbiol Infect Dis. 2012;74:384-7.

18. Jin Y, Yuan XH, Xie ZP, Gao HC, Song JR, Zhang RF, et al. Prevalence and clinical characterization of a newly identified human rhinovirus $C$ species in children with acute respiratory tract infections. J Clin Microbiol. 2009;47: 2895-900.

19. Yoshida LM, Suzuki M, Nguyen HA, Le MN, Dinh Vu T, et al. Respiratory syncytial virus: co-infection and paediatric lower respiratory tract infections. Eur Respir J. 2013;42:461-9.
20. Linsuwanon P, Payungporn S, Samransamruajkit R, Posuwan N, Makkoch J, Theanboonlers $\mathrm{A}$, et al. High prevalence of human rhinovirus $\mathrm{C}$ infection in Thai children with acute lower respiratory tract disease. J Infect. 2009:59:115-21.

21. Zeng SZ, Xiao NG, Xie ZP, Xie GC, Zhong LL, Wang J, et al. Prevalence of human rhinovirus in children admitted to hospital with acute lower respiratory tract infections in Changsha, China. J Med Virol. 2014;86:1983-9.

22. Linder JE, Kraft DC, Mohamed Y, Lu Z, Heil L, Tollefson S, et al. Age, season, and lower respiratory illness over the past three decades. J Allergy Clin Immunol. 2013:131:69-77.

23. Miller EK, Gebretsadik T, Carroll KN, Dupont WD, Mohamed YA, Morin LL, et al. Viral etiologies of infant bronchiolitis, croup and upper respiratory illness during four consecutive years. Pediatr Infect Dis J. 2013;32:950-5.

24. García-García ML, Calvo C, Pozo F, Villadangos PA, Pérez-Breña P, Casas I. Spectrum of respiratory viruses in children with community acquired pneumonia. Pediatr Infect Dis J. 2012:8:808-13.

25. Gern JE. The ABCs of rhinoviruses, wheezing, and asthma. J Virol. 2010;84: 7418-26.

26. Mak RKY, Tse LY, Lam WY, Wong GWK, Chan PKS, Leung TF. Clinical spectrum of human rhinovirus infections in hospitalized Hong Kong children. Pediatr Infect Dis J. 2011:30:749-53.

27. Calışkan M, Bochkov YA, Kreiner-Møller E, Bønnelykke K, Stein MM, Du G, et al. Rhinovirus wheezing illness and genetic risk of childhood-onset asthma. N Engl J Med. 2013;368:1398-407.

28. Piralla A, Rovida F, Campanini G, Rognoni V, Marchi A, Locatelli F, et al. Clinical severity and molecular typing of human rhinovirus $C$ strains during a fall outbreak affecting hospitalized patients. J Clin Virol. 2009:45:311-7.

29. Lau SKP, Yip CCY, Lin AWC, Lee RA, So L-Y, Lau Y-L, et al. Clinical and molecular epidemiology of human rhinovirus $C$ in children and adults in Hong Kong reveals a possible distinct human rhinovirus C subgroup. J Infect Dis. 2009;200: 1096-103.

30. Jacobs SE, Lamson DM, St George K, Walsh TJ. Human rhinoviruses. Clin Microbiol Rev. 2013;26:135-62.

31. Karim YG, ljaz MK, Sattar SA, Johnson-Lussenburg CM. Effect of relative humidity on the airborne survival of rhinovirus-14. Can J Microbiol. 1985;31:1058-61.

32. Milton DK, Glencross PM, Walters MD. Risk of sick leave associated with outdoor air supply rate, humidification, and occupant complaints. Indoor Air. 2000:10:212-21.

\section{Submit your next manuscript to BioMed Central and we will help you at every step:}

- We accept pre-submission inquiries

- Our selector tool helps you to find the most relevant journal

- We provide round the clock customer support

- Convenient online submission

- Thorough peer review

- Inclusion in PubMed and all major indexing services

- Maximum visibility for your research

Submit your manuscript at www.biomedcentral.com/submit
C) Biomed Central 